\title{
Non-invasive in vivo Imaging Grading of Liver Fibrosis
}

\author{
Hanyu Jiang\# ${ }^{\#}$ Tianying Zheng" ${ }^{\#}$ Ting Duan, Jie Chen and Bin Song* \\ Department of Radiology, Sichuan University West China Hospital, Chengdu, China
}

\begin{abstract}
Liver fibrosis (LF), a common consequence of chronic liver diseases with various etiologies, is characterized by excessive accumulation of macromolecules, including collagen, glycoproteins and proteoglycans, in the liver. LF can result in hepatic dysfunction, cirrhosis, portal hypertension and, in some cases, hepatocellular carcinoma. As the current gold standard for diagnosing LF, liver biopsy, however, is invasive and prone to sampling errors and procedure-related complications. Therefore, developing noninvasive, precise and reproducible imaging tests for diagnosing and staging LF is of great significance. Conventional ultrasound (US), computed tomography (CT) and magnetic resonance (MR) imaging can depict morphological alterations of advanced $L F$, but have relatively limited capability characterizing early-stage LF. In order to optimize the diagnostic performances of noninvasive imaging techniques for LF across its entire spectrum of severity, a number of novel methods, including US elastography, CT perfusion imaging and various MR imaging-based techniques, have been established and introduced to clinical practice. In this review, we intended to summarize current noninvasive imaging techniques for $L F$, with special emphasis on the possible roles, advantages and limitations of the new emerging imaging modalities.
\end{abstract}

Citation of this article: Jiang $\mathrm{H}$, Zheng $\mathrm{T}$, Duan $\mathrm{T}$, Chen $\mathrm{J}$, Song $B$. Non-invasive in vivo imaging grading of liver fibrosis. J Clin Transl Hepatol 2018;6(2):198-207. doi: 10.14218/JCTH. 2017.00038.

\section{Introduction}

Liver fibrosis (LF) is a characteristic consequence of repetitive liver parenchymal damage triggered by various etiologies, and is typified by excessive accumulation of macromolecules, such as collagens, glycoproteins and proteoglycans, in the

Keywords: Liver cirrhosis; Ultrasonography; Computed tomography; Magnetic resonance imaging.

Abbreviations: 2D-SWE, Two-dimensional shear wave elastography; ADC, apparent diffusion coefficient; AUROC, area under the receiver operating characteristic curve; CLD, chronic liver disease; CT, computed tomography; CEUS, contrastenhanced US; DWI, diffusion-weighted MR imaging; Gd-EOB-DTPA, gadoxetic acid disodium; HBP, hepatobiliary phase; HBV, hepatitis B virus; HCC, hepatocellular carcinoma; $\mathrm{HCV}$, hepatitis $\mathrm{C}$ virus; $\mathrm{HV}$, hepatic vein; HVAT, hepatic vein arrival time; LF, liver fibrosis; MR, magnetic resonance; NAFLD, nonalcoholic fatty liver disease; pSWE, point shear wave elastography; ROI, region of interest; SWI, shear wave imaging; TE, transient elastography; US, ultrasound.

Received: 5 June 2017; Revised: 25 October 2017; Accepted: 29 November 2017 \#These authors contributed equally to this work.

*Correspondence to: Bin Song, Department of Radiology, Sichuan University West China Hospital, No. 37 Guoxue Alley, Chengdu, Sichuan 610041, China Tel: +86-28-85423680,+86-13881918066, E-mail: anicesong@vip.sina.com liver extracellular matrix ${ }^{1}$ (Fig. 1). Currently, alcoholic liver disease, chronic hepatitis $B$ and chronic hepatitis $C$ are the most prevalent causes of LF. ${ }^{2,3}$ LF can result in progressive hepatic dysfunction, cirrhosis, portal hypertension and, in some cases, hepatocellular carcinoma (HCC). ${ }^{2}$ Currently, although very limited treatment options beyond liver transplantation are effective for end-stage LF, early-stage LF is usually a treatable condition. ${ }^{4}$ Thus, as prognosis and patient management of chronic liver diseases (CLDs) are strongly related to LF severity, early and accurate diagnosis of LF is of great importance in clinical practice.

Liver biopsy, a standard procedure of obtaining liver tissue for histopathological assessment, is the gold standard for LF currently. ${ }^{5}$ The most widely adopted classifying system for LF triggered by chronic autoimmune and viral hepatitis is the METAVIR scoring system, where the spectrum of LF severity is divided into five stages, from no fibrosis (F0) to cirrhosis (F4). ${ }^{6}$ Accurate as it is, liver biopsy is invasive and limited by inter- and intra-observer variability, and sampling errors. ${ }^{5,7}$ Besides, liver biopsy can lead to various complications and requires considerable operator expertise. Therefore, the introduction of noninvasive diagnostic approaches is pivotal to address the above limitations of liver biopsy.

Imaging approaches comprising ultrasound (US), computed tomography $(\mathrm{CT})$ and magnetic resonance (MR) imaging have been playing significant roles in the assessment of LF for the past decades. The introductions of elastography and several CT and MR-based techniques have further improved the diagnostic performances for LF. In this review, we focused on noninvasive imaging evaluation of LF, with special emphasis on the roles of new emerging imaging techniques.

\section{Noninvasive imaging evaluation of LF}

Noninvasive imaging approaches allow detection, staging and monitoring of LF. Morphologic alterations of the liver and signs of portal hypertension are the most significant imaging manifestations of end-stage LF (Table 1) with high specificity. However, these signs demonstrate limited sensitivity and are visible only in advanced cases, thus not being accurate for staging LF over its entire spectrum of severity. ${ }^{8,9}$ In patients with less advanced $L F$, the liver parenchyma is usually normal in appearance or exhibits only subtle, nonspecific heterogeneity. In addition, extrahepatic findings, which may include ascites, splenomegaly and portosystemic varices, may be present in other conditions, hence not being specific for LF. ${ }^{10}$ Luckily, novel emerging imaging techniques are being validated to measure LF, as discussed below. Advantages and limitations of each imaging modality are documented in Table 2. 


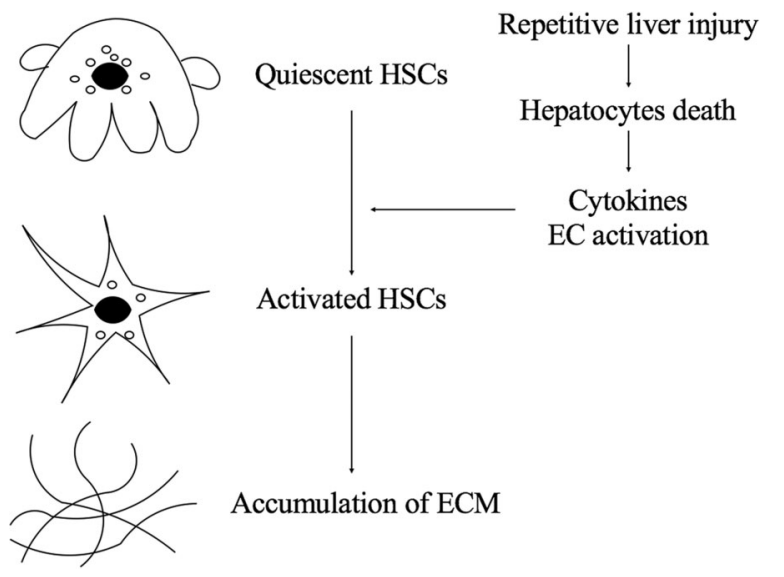

Fig. 1. Mechanism of liver fibrosis. As a result of continuous liver injury, activation of vitamin A-rich quiescent hepatic stellate cells induced by necrosis and apoptosis of hepatocytes triggers accumulation of extracellular matrix. EC, endothelial cell; HSCs, hepatic stellate cells.

\section{US}

Conventional US: Gray-scale and Doppler US are the conventional US techniques used as first-line imaging examinations for patients with suspected LF. These methods are easy to perform, real-time, noninvasive, reproducible, inexpensive, well validated and widely available, with no ionizing radiation. Besides, they are highly sensitive in detecting portal and hepatic vein thrombosis. ${ }^{11}$ Parameters comprising liver surface nodularity, altered liver size and/or splenomegaly, bluntness of liver edge, altered liver parenchymal echogenicity with coarsened echotexture, and altered portal vein blood

Table 1. Imaging signs of liver fibrosis

\begin{tabular}{|c|c|}
\hline \multirow[t]{5}{*}{ Liver morphology } & $\begin{array}{l}\text { Nodular liver surface } \\
\text { (surface nodularity) }\end{array}$ \\
\hline & Heterogeneous parenchyma \\
\hline & $\begin{array}{l}\text { Expanded gallbladder fossa } \\
\text { Altered liver size }\end{array}$ \\
\hline & $\begin{array}{l}\text { Hypertrophy of caudate lobe } \\
\text { and left lobe }\end{array}$ \\
\hline & $\begin{array}{l}\text { Atrophy of the segment IV and } \\
\text { medial segment of left hepatic lobe }\end{array}$ \\
\hline Hepatic artery & Increased diameter and tortuosity \\
\hline Hepatic veins & $\begin{array}{l}\text { Decreased diameter and altered } \\
\text { straightness }\end{array}$ \\
\hline $\begin{array}{l}\text { Portal venous } \\
\text { system }\end{array}$ & $\begin{array}{l}\text { Dilation of portal, splenic and } \\
\text { superior mesenteric veins }\end{array}$ \\
\hline Spleen & Splenomegaly \\
\hline $\begin{array}{l}\text { Portosystemic } \\
\text { collateral } \\
\text { circulation }\end{array}$ & $\begin{array}{l}\text { Formation of gastroesophogeal, } \\
\text { paraesophogeal, left gastric, } \\
\text { short gastric, umbilical and } \\
\text { abdominal wall varices with } \\
\text { engorged and tortuous appearance } \\
\text { Splenorenal/gastrorenal shunts } \\
\text { and retroperitoneal shunts }\end{array}$ \\
\hline
\end{tabular}

Ascites flow velocity and effective portal liver perfusion, have been suggested to be useful in evaluating LF. ${ }^{11,12}$

However, the diagnostic capacity of conventional US in LF can be limited due to considerable interobserver variability, low specificity, and interference by intestinal gas and obesity. ${ }^{13}$ Besides, the Doppler US can be affected by patient respiration, fasting status, collateral pathways, hepatic steatosis and inflammation. ${ }^{14,15}$

Contrast-enhanced US (CEUS): CEUS is an emerging US modality based on intravenous administration of specific contrast agents. The contrast media are gas-filled microbubbles which significantly enhance the intravascular blood flow against other tissues. ${ }^{8,16}$ It allows for the evaluation of hemodynamic changes during LF evolution. The hepatic vein arrival time (HVAT), defined as the time taken for the contrast media to reach the hepatic vein (HV) after injection, was reported to have negative correlations with the severity of LF or portal hypertension. ${ }^{17,18}$ As LF evolves, increased formation of sinusoid capillaries and arterio-/portovenous shunts can result in decreased HVAT. ${ }^{16}$ Kim et al. ${ }^{19}$ reported that, HVAT was negatively correlated with HV pressure gradient $\left(r^{2}=0.545, p<\right.$ 0.001 ), and that with 14 seconds as a cut-off value, HVAT achieved sensitivity, specificity and the area under the receiver operating characteristic curve (AUROC) of $0.927,0.867$ and 0.973 , respectively, for evaluating clinically significant portal hypertension. In addition, a shorter HVAT was significantly associated with esophageal varices and worse Child-Pugh score.

CEUS is a simple and noninvasive approach for characterizing hemodynamic changes of LF and portal hypertension. However, CEUS is more expensive than conventional US and requires injection of corresponding intravenous contrast agents and considerable operator expertise. These disadvantages may limit its application in routine clinical practice.

US elastography: Imaging-based elastography is an emerging technology that measures tissue stiffness and other mechanical properties noninvasively. ${ }^{20,21}$ Evaluated with elastography, share wave has particle motion perpendicular to the direction in which the wave propagates. The traveling velocity of shear waves has been validated to correlate with tissue stiffness: shear waves travel faster in stiff tissues (inflamed or fibrotic liver) and slower in soft tissues (normal or fatty liver). ${ }^{22,23}$ US elastography is able to assess liver stiffness, which increases due to fibrosis in CLDs, by tracking and measuring the speed of shear waves via liver parenchyma. Currently, shear wave imaging (SWI) is the most widely used US elastography technique for evaluating LF. SWI permits quantitative assessment of tissue stiffness and stiffness-related parameters by tracking shear waves propagating through the liver. ${ }^{20}$

Three major SWI-based techniques, including transient elastography (TE), point shear wave elastography (pSWE) and two-dimensional shear wave elastography (2D-SWE), are commercially available today. ${ }^{24}$ Among these approaches, TE is not an imaging technique, while pSWE and 2D-SWE are both imaging techniques incorporated in US scanners.

TE is the first US-based type. TE is widely available and well validated in hepatitis $\mathrm{C}$ virus (HCV) and chronic alcoholic liver disease-related $L F$, and to a lesser extent in hepatitis $B$ virus (HBV) and nonalcoholic fatty liver disease (NAFLD) patients. ${ }^{25-27}$ In TE, liver stiffness is evaluated by tracking the speed of shear waves propagating through the liver. The shear waves are generated by an ultrasound transducer, which is usually placed through an intercostal space above the right liver lobe. Propagation of the shear wave is tracked with its speed measured and the tissue stiffness reported in 
Jiang $\mathrm{H}$. et al: Imaging grading of liver fibrosis

Table 2. Major advantages and limitations of available non-invasive imaging methods used for liver fibrosis evaluation

\begin{tabular}{|c|c|c|c|}
\hline Test & & Advantages & Limitations \\
\hline \multirow[t]{5}{*}{ Ultrasound } & \multirow[t]{3}{*}{$\begin{array}{l}\text { Conventional } \\
\text { ultrasound }\end{array}$} & $\begin{array}{l}\text { Widely available and inexpensive } \\
\text { real-time }\end{array}$ & $\begin{array}{l}\text { Considerable interobserver } \\
\text { variability } \\
\text { Relatively low specificity }\end{array}$ \\
\hline & & $\begin{array}{l}\text { Reproducible and without ionizing } \\
\text { radiation } \\
\text { Highly sensitive in detecting portal } \\
\text { and hepatic vein thrombosis }\end{array}$ & $\begin{array}{l}\text { Interference by intestinal gas, } \\
\text { obesity, patient respiration, fasting } \\
\text { status, collateral pathways, } \\
\text { hepatic steatosis and } \\
\text { inflammation }\end{array}$ \\
\hline & & $\begin{array}{l}\text { Able to measure intrahepatic and } \\
\text { systemic hemodynamic changes }\end{array}$ & \\
\hline & \multirow[t]{2}{*}{$\begin{array}{l}\text { Contrast- } \\
\text { enhanced } \\
\text { ultrasound }\end{array}$} & \multirow{2}{*}{$\begin{array}{l}\text { Able to measure intrahepatic } \\
\text { and systemic hemodynamic } \\
\text { changes with better contrast } \\
\text { than Doppler US }\end{array}$} & $\begin{array}{l}\text { Require injection of intravenous } \\
\text { contrast agents and operator } \\
\text { expertise }\end{array}$ \\
\hline & & & $\begin{array}{l}\text { More expensive than conventional } \\
\text { ultrasound }\end{array}$ \\
\hline \multirow[t]{7}{*}{$\begin{array}{l}\text { Ultrasound } \\
\text { elastography }\end{array}$} & \multirow[t]{2}{*}{$\begin{array}{l}\text { Transient } \\
\text { elastography }\end{array}$} & \multirow[t]{2}{*}{$\begin{array}{l}\text { Widely available and well validated } \\
\text { in most etiologies of chronic liver } \\
\text { diseases } \\
\text { Highly portable } \\
\text { Shear wave frequency well } \\
\text { controlled }\end{array}$} & $\begin{array}{l}\text { No anatomic images captured or } \\
\text { the exact measurement location } \\
\text { recorded during examination } \\
\text { Restricted to patients with no } \\
\text { obesity, narrow intercostal space } \\
\text { or ascites }\end{array}$ \\
\hline & & & $\begin{array}{l}\text { Lack standardized cut-offs for each } \\
\text { liver fibrosis stage }\end{array}$ \\
\hline & \multirow[t]{2}{*}{$\begin{array}{l}\text { Point shear } \\
\text { wave } \\
\text { elastography }\end{array}$} & $\begin{array}{l}\text { Manually selected ROI allows } \\
\text { quantitative analysis of liver } \\
\text { stiffness and enables more reliable } \\
\text { monitoring with less sampling } \\
\text { variability }\end{array}$ & $\begin{array}{l}\text { More expensive and expertise } \\
\text { required, whereas less validated } \\
\text { than transient elastography }\end{array}$ \\
\hline & & $\begin{array}{l}\text { Generates more robust shear } \\
\text { waves than transient elastography } \\
\text { Can be applied in patients with } \\
\text { obesity or ascites }\end{array}$ & $\begin{array}{l}\text { Shear wave frequency is hard to } \\
\text { control and therefore may } \\
\text { introduce measurement variability }\end{array}$ \\
\hline & \multirow[t]{3}{*}{$\begin{array}{l}\text { 2D-shear } \\
\text { wave } \\
\text { elastography }\end{array}$} & $\begin{array}{l}\text { Ultrafast imaging allows } \\
\text { generation of real-time } \\
\text { quantitative elastograms }\end{array}$ & \multirow[t]{3}{*}{$\begin{array}{l}\text { Same limitations as point shear } \\
\text { wave elastography }\end{array}$} \\
\hline & & $\begin{array}{l}\text { Several ROIs can be placed on the } \\
\text { elastograms }\end{array}$ & \\
\hline & & Reduced sampling variability & \\
\hline \multirow{5}{*}{$\begin{array}{l}\text { Computed } \\
\text { tomography }\end{array}$} & \multirow{3}{*}{$\begin{array}{l}\text { Conventional } \\
\text { computed } \\
\text { tomography }\end{array}$} & Widely available and well validated & Ionizing radiation exposure \\
\hline & & $\begin{array}{l}\text { Allows a full cross-sectional } \\
\text { visualization }\end{array}$ & $\begin{array}{l}\text { Require injection of intravenous } \\
\text { contrast agents }\end{array}$ \\
\hline & & $\begin{array}{l}\text { Signs of morphologic liver } \\
\text { alterations, cirrhosis and portal } \\
\text { hypertension are specific }\end{array}$ & $\begin{array}{l}\text { Not sensitive enough to detect and } \\
\text { stage less advanced fibrosis }\end{array}$ \\
\hline & \multirow{2}{*}{$\begin{array}{l}\text { Computed } \\
\text { tomography } \\
\text { perfusion } \\
\text { imaging }\end{array}$} & \multirow[t]{2}{*}{$\begin{array}{l}\text { Allows quantitative measurement } \\
\text { regional and systemic } \\
\text { hemodynamic changes }\end{array}$} & $\begin{array}{l}\text { Less available or validated than } \\
\text { conventional computed } \\
\text { tomography }\end{array}$ \\
\hline & & & $\begin{array}{l}\text { More expensive and more } \\
\text { expertise required than } \\
\text { conventional computed } \\
\text { tomography }\end{array}$ \\
\hline
\end{tabular}


Table 2. (continued)

\begin{tabular}{|c|c|c|c|}
\hline Test & & Advantages & Limitations \\
\hline \multirow[t]{12}{*}{$\begin{array}{l}\text { Magnetic } \\
\text { resonance } \\
\text { imaging }\end{array}$} & $\begin{array}{l}\text { Conventional } \\
\text { magnetic } \\
\text { resonance } \\
\text { imaging }\end{array}$ & $\begin{array}{l}\text { No ionizing radiation } \\
\text { Liver fibrosis manifests a specific } \\
\text { enhancement pattern } \\
\text { Aids in differentiation of focal } \\
\text { fibrosis from cirrhosis-related } \\
\text { vascular lesions }\end{array}$ & $\begin{array}{l}\text { More expensive and time- } \\
\text { consuming than conventional } \\
\text { computed tomography } \\
\text { Elevated risk of nephrogenic } \\
\text { systemic sclerosis due to } \\
\text { gadolinium contrast agent } \\
\text { injection }\end{array}$ \\
\hline & $\begin{array}{l}\text { Magnetic } \\
\text { resonance } \\
\text { elastography }\end{array}$ & $\begin{array}{l}\text { High diagnostic accuracy for } \\
\text { advanced fibrosis and cirrhosis } \\
\text { Robust } \\
\text { Can be applied in patients with } \\
\text { obesity and/or ascites } \\
\text { Able to assess a larger proportion } \\
\text { of the liver than ultrasound } \\
\text { elastography, which may reduce } \\
\text { sampling variability for patient } \\
\text { monitoring }\end{array}$ & $\begin{array}{l}\text { High cost and time-consuming } \\
\text { Limited availability } \\
\text { Limited application in patients with } \\
\text { iron overload, steatosis, vascular } \\
\text { congestion or cholestasis } \\
\text { Acquired with inconsistent breath } \\
\text { holds } \\
\text { Insufficient evidence regarding its } \\
\text { diagnostic performances }\end{array}$ \\
\hline & $\begin{array}{l}\text { Diffusion } \\
\text { weighted } \\
\text { magnetic } \\
\text { resonance } \\
\text { imaging }\end{array}$ & $\begin{array}{l}\text { Widely available and relatively } \\
\text { easy to perform } \\
\text { Reproducible } \\
\text { Robust } \\
\text { Apparent diffusion coefficient well } \\
\text { correlated with liver fibrosis stage } \\
\text { Intravoxel incoherent motion } \\
\text { model can add additional } \\
\text { diagnostic benefits }\end{array}$ & $\begin{array}{l}\text { Results may be influenced by } \\
\text { perfusion effects, hepatic } \\
\text { steatosis, edema, iron } \\
\text { accumulation and liver } \\
\text { inflammation } \\
\text { Sensitive to susceptibility and } \\
\text { motion-related artifacts } \\
\text { Acquisition relies significantly on } \\
\text { several imaging parameters } \\
\text { including field strength and b } \\
\text { values }\end{array}$ \\
\hline & \multirow[t]{4}{*}{$\begin{array}{l}\text { Gadoxetic } \\
\text { acid } \\
\text { disodium }\end{array}$} & $\begin{array}{l}\text { Provides both hemodynamic } \\
\text { information and lesion function } \\
\text { information in a single } \\
\text { examination }\end{array}$ & \multirow[t]{4}{*}{$\begin{array}{l}\text { Less validated than nonspecific } \\
\text { gadolinium chelates } \\
\text { Hepatobiliary phase hypointensity } \\
\text { is not specific for hepatocellular } \\
\text { carcinoma }\end{array}$} \\
\hline & & $\begin{array}{l}\text { High diagnostic accuracy for focal } \\
\text { liver lesions }\end{array}$ & \\
\hline & & $\begin{array}{l}\text { Early detection of hepatocellular } \\
\text { carcinoma }\end{array}$ & \\
\hline & & $\begin{array}{l}\text { Can measure preoperative liver } \\
\text { function }\end{array}$ & \\
\hline & \multirow{5}{*}{$\begin{array}{l}\text { Magnetic } \\
\text { resonance } \\
\text { perfusion } \\
\text { imaging }\end{array}$} & \multirow{5}{*}{$\begin{array}{l}\text { Allows quantitative measurement } \\
\text { of regional and systemic } \\
\text { hemodynamic changes }\end{array}$} & Time-consuming \\
\hline & & & $\begin{array}{l}\text { Less available or validated than } \\
\text { conventional magnetic resonance } \\
\text { imaging }\end{array}$ \\
\hline & & & $\begin{array}{l}\text { Can be affected by the cardiac } \\
\text { status, fasting state, hepatic } \\
\text { congestion, inflammation, liver } \\
\text { masses, and hepatic portal venous } \\
\text { flow }\end{array}$ \\
\hline & & & $\begin{array}{l}\text { Image quality not sufficient for } \\
\text { assessing small nodules }\end{array}$ \\
\hline & & & $\begin{array}{l}\text { May require a second contrast } \\
\text { material injection }\end{array}$ \\
\hline
\end{tabular}


the form of kilopascals $(\mathrm{kPa})$. A shear-wave propagation graph is displayed after each acquisition.

It has been suggested that TE is useful in discriminating no and mild fibrosis (F0-F1) from advanced fibrosis and cirrhosis (F3-F4); however, the accuracy is poor among the early stages of LF. Sporea et al. ${ }^{28}$ included 199 consecutive patients and reported that, compared with liver biopsy, an optimal cutoff value of $6.8 \mathrm{kPa}$ could achieve $59.6 \%$ sensitivity and $93.3 \%$ specificity for significant fibrosis ( $\geq F 2$ ), with an AUROC of 0.773 . Their study indicated that $6.8 \mathrm{kPa}$ was the best cut-off value to distinguish significant fibrosis from no or mild fibrosis, with acceptable diagnostic accuracy.

In order to further explore the diagnostic accuracy and determine optimal cut-off values of TE for LF assessment, several meta-analyses have been conducted. Friedrich-Rust et al. ${ }^{29}$ investigated 50 studies and reported that for the detection of significant fibrosis ( $\geq F 2$ ), TE demonstrated an AUROC of 0.84 with an optimal cut-off value of $7.6 \mathrm{kPa}$, while for cirrhosis (F4), the best cut-off value was $13 \mathrm{kPa}$ with an AUROC of 0.94 . However, with 40 studies analyzed, Tsochatzis et al. ${ }^{30}$ reported that, although pooled sensitivity and specificity was 0.79 and 0.78 for $F 2$ and 0.83 and 0.89 for F4, no optimal cut-off for individual fibrosis stage was achieved because cut-offs ranged widely and presented significant overlaps within and between LF stages. Their studies implied that, for each LF stage, the best cut-off values are difficult to determine because these values are highly dependent on the etiology of CLD.

Recently, TE has been recommended by the American Gastroenterological Association, European Association for the Study of Liver and European Federation of Societies for Ultrasound in Medicine and Biology guidelines to be useful in assessing CLDs and chronic viral hepatitis-related LF. ${ }^{31}$ The American Gastroenterological Association guidelines recommended $12.5( \pm 1) \mathrm{kPa}$ as the optimal cut-off value for diagnosis of cirrhosis (F4) in patients with chronic HCV infection and alcoholic liver disease, whereas $11.0( \pm 1) \mathrm{kPa}$ is recommended for chronic HBV patients. ${ }^{32}$ Moreover, the European Federation of Societies for Ultrasound in Medicine and Biology guidelines issued values above $6.8-7.6 \mathrm{kPa}$ as being highly correlated with the presence of significant fibrosis $(\geq F 2)$ and that those ranging between $11.0-13.6 \mathrm{kPa}$ may indicate cirrhosis (F4). ${ }^{33}$ Several algorithms combining TE and serum biomarkers have been proposed to increase diagnostic accuracy and reduce the number of biopsies, mainly in viral hepatitis. ${ }^{34-36}$ Recently, the European Association for the Study of Liver-ALEH have suggested algorithms for noninvasive tests in first-line fibrosis staging in patients with hepatitis B and C infections ${ }^{37}$ (Fig. 2).

TE is relatively inexpensive, highly portable, widely available, reproducible and easy to perform. However, the technique lacks standardized cut-offs for each fibrosis stage and may be limited in patients with ascites, obesity or narrow intercostal space. Most importantly, the exact measurement locations are not recorded because no anatomic image is captured with $T E$, which may introduce sampling variability for monitoring LF progress over time.

PSWE is a novel US elastography technique incorporated into conventional US scanners. In pSWE, a region of interest (ROI) of the liver is excited by a high-frequency acoustic radiation force impulse mechanically. This impulse causes tissue expansion and generates shear waves propagating perpendicular to the ultrasound beam axis. ${ }^{38,39}$ The speed of the shear wave is measured and reported in $\mathrm{m} / \mathrm{s}$, with a range between $0.5-5 \mathrm{~m} / \mathrm{s}$ in different abdominal conditions. ${ }^{40}$
pSWE has been applied to assess LF of various etiologies in clinical practice. Recently, a meta-analysis of 1163 patients compared the diagnostic performances of TE and pSWE for LF. It reported that for diagnosing significant fibrosis ( $\geq F 2$ ), the pooled sensitivity was 0.74 and specificity 0.83 for pSWE; while for TE, the summarized sensitivity and specificity was 0.78 and 0.84 , respectively. In cases with cirrhosis (F4), the pooled sensitivity and specificity were 0.87 and 0.87 for PSWE, respectively, and 0.89 and 0.87 for TE. Their study demonstrated no statistically significant difference between the diagnostic accuracies of pSWE and TE for significant fibrosis ( $\geq F 2$ ) or cirrhosis (F4). ${ }^{41}$

pSWE possesses several advantages. First, this technique permits quantitative evaluation of liver stiffness in a manually selected ROI, which enables more reliable patient monitoring and follow-up. Second, because the shear waves are generated locally within the liver, pSWE is more robust than TE and thus can be applied in patients with obesity and/or ascites. However, pSWE is more expensive, requires more expertise to perform, and is less available and validated by current studies compared with TE. Besides, the shear wave frequency is difficult to control precisely in the setting of pSWE, which is likely to introduce measurement variability.

2D-SWE technique, as the currently newest SWI-based method, applies acoustic radiation force focused at successively greater depths on an axial line to stimulate microscopic tissue movements and generate shear waves. ${ }^{42}$ The entire imaging plane is scanned with high temporal resolution in one acquisition by an ultrafast imaging technique. This allows the real-time generation of quantitative elastograms. ${ }^{43,44}$ Shear wave speed $(\mathrm{m} / \mathrm{s})$ or Young's modulus (kilopascal) are reported to depict tissue stiffness in 2D-SWE.

Much effort has been devoted to comparing the diagnostic performances of 2D-SWE and other SWI-based methods for staging LF. ${ }^{44-48}$ Leung et al. ${ }^{46}$ investigated 226 patients and 171 healthy patients with liver biopsy as a reference standard. They reported the superiority of 2D-SWE over TE in diagnostic accuracy of all fibrosis stages. The AUROCs for 2D-SWE and $T E$, respectively, were 0.86 and 0.80 for $L F \geq F 1,0.88$, and 0.78 for $\geq F 2,0.93$ and 0.83 for $\geq F 3$, and 0.98 and 0.92 for F4. However, another study comparing the diagnostic potential of TE, pSWE and 2D-SWE for LF found no statistically significant diagnostic difference between TE, pSWE or 2D-SWE for $L F \geq F 2$ and $F 4$ with 332 patients. ${ }^{45}$

2D-SWE can be applied in patients with ascites and is able to analyze multiple ROIs according to the elastograms, which reduces some of the possible sampling variability with TE and pSWE. Nevertheless, the applications of 2D-SWE in LF may have been limited due to its restricted availability and insufficient evidence concerning its diagnostic performance. Moreover, it is more expensive and requires more operator expertise. Therefore, further studies and intensive validations are encouraged to demonstrate its concrete role in LF staging and monitoring of its potential clinical superiority.

\section{CT}

CT and MR imaging are useful cross-sectional imaging modalities for LF. The diagnosis, staging and surveillance of HCC, a major consequence of CLDs and LF, are primarily established by multiphasic CT or contrast-enhanced MR imaging findings. ${ }^{49,50}$ Liver morphology changes, signs of cirrhosis and portal hypertension can be directly evaluated by $\mathrm{CT}$ in patients with endstage LF, as mentioned above (Table 1) (Fig. 3). However, CT is 

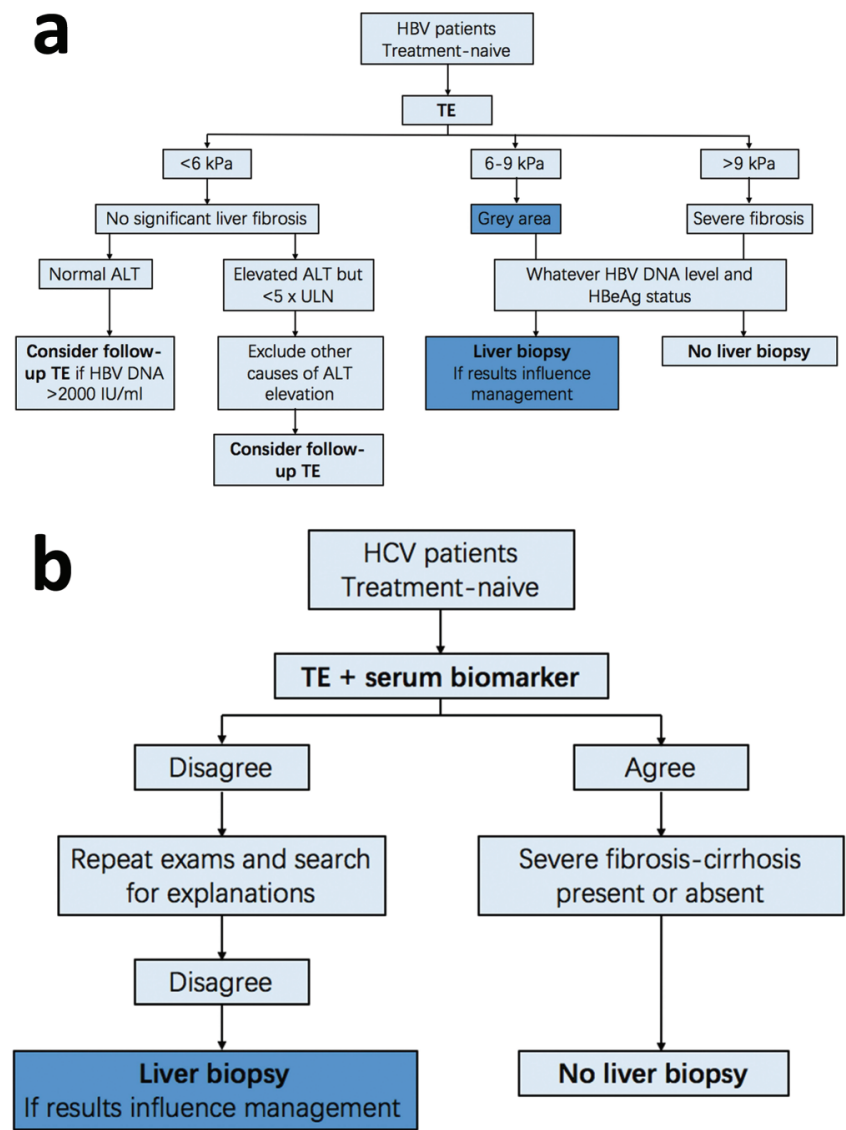

Fig. 2. Algorithms for noninvasive tests in first-line fibrosis staging of patients with hepatitis $B(a)$ and $C(b)$ infection suggested by the European Association for the Study of Liver-ALEH. Modified from EASL-ALEH Clinical Practice Guidelines. ${ }^{37}$ Abbreviations: ALT, alanine aminotransferase; HBV hepatitis $B$ virus; $H C V$, hepatitis $C$ virus; $T E$, transient elastography.

not sensitive enough to detect and discriminate less advanced fibrosis.

CT perfusion imaging is a functional CT-based imaging technique which permits quantitative measurements of the hepatic and systemic hemodynamic changes in patients with LF. ${ }^{51-53}$ One study with 21 cirrhosis patients demonstrated that two parameters-splenic arterial flow and splenic clearance-were inversely correlated with hepatic venous pressure gradient, and that a splenic clearance cut-off value of $125 \mathrm{ml} / \mathrm{min} / 100 \mathrm{~mL}$ yielded $94 \%$ sensitivity and $100 \%$ specificity for severe portal hypertension. ${ }^{51}$ This study suggested that CT perfusion can be applied to quantitatively evaluate portal hypertension in patients with LF.

\section{MR imaging}

MR imaging has been widely applied and well validated to assess LF and its complications. Nevertheless, early detection and accurate grading of LF with the use of MR imaging remains one of the major challenging areas in liver imaging. Recently, several novel MR techniques have been introduced for this purpose.

Conventional MR imaging: Like CT, widely applied conventional MR imaging is able to identify liver morphology changes, signs of cirrhosis and portal hypertension in patients with advanced cirrhosis of various etiologies (Table 1). Administration of intravenous gadolinium-based contrast agents can further improve the visibility of LF and its related complications. On T1-weighted images, LF is often hyperintense. ${ }^{54}$ Moreover, LF usually displays a distinctive progressive enhancement pattern, of which the peak enhancement is usually observed during the late venous and equilibrium phases. ${ }^{54}$ However, cirrhosis-related vascular lesions, such as HCC and arterioportal shunts, can result in diagnostic confusion over focal fibrosis. Some imaging features may aid in the differential diagnosis. Presence of the specific enhancement pattern, reticular appearance and wedge-shaped configuration usually favor a diagnosis of LF. ${ }^{54}$

MR elastography: MR elastography is an emerging MRbased imaging modality which quantifies tissue stiffness noninvasively by assessing the propagation of mechanical waves through media ${ }^{55}$ (Fig. 4). As the shear waves propagate through the liver parenchyma, MR images are acquired with the use of a gradient-echo sequence. Similar to US elastography, the speed and wavelength of the shear wave through liver tissue in MR elastography is positively correlated with tissue stiffness. ${ }^{56}$ Therefore, liver stiffness can be evaluated by placing and measuring ROIs on the elastograms manually.
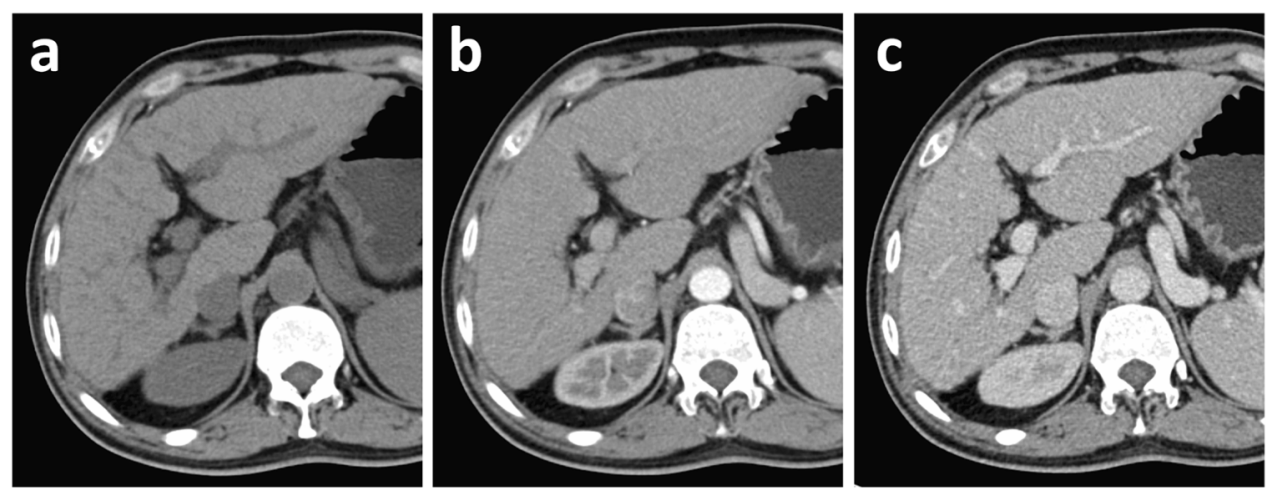

Fig. 3. Morphologic liver changes in a 51-year-old male patient diagnosed with HBV-related liver cirrhosis. The patient presented with anorexia and nausea for 6 years, as well as melena and fatigue for 1 year. Nonenhanced (a), arterial phase (b) and portal phase (c) CT images show surface nodularity, widening of fissures, atrophy of the right lobe, and relative enlargement of the left lobe. 


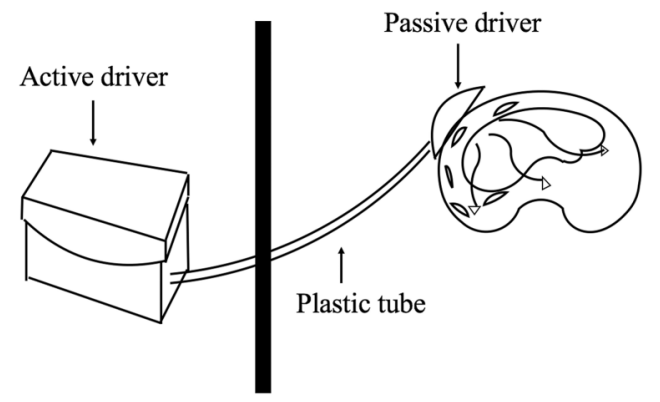

Control room

Scanner room

Fig. 4. Illustration of the mechanical driver device in MR elastography The system is composed of the active driver in the control room that generates compressions waves, which are transmitted through a plastic tube to the passive driver in the scanner room placed adjacent to the patient's right anterior body wall that generates shear waves and the direction of shear wave propagation (curved arrows).

MR elastography has been validated for the assessment of LF since its introduction. ${ }^{57-59}$ A prospective study ${ }^{58}$ demonstrated that the diagnostic performance of MR elastography for LF was significantly better than that of ultrasound elasticity, pSWE, or the combination of ultrasound elasticity and pSWE. Other prospective studies ${ }^{59,60}$ reported that the frequency-independent cut-off values of MR elastography were $2.84 \mathrm{kPa}$ for $\mathrm{LF} \geq \mathrm{F} 1,3.18 \mathrm{kPa}$ for $\geq F 2,3.32 \mathrm{kPa}$ for $\geq F 3$ and $4.21 \mathrm{kPa}$ for F4. The AUROCs were $0.9128,0.9244,0.9744$ and 0.9931 for $L F \geq F 1, \geq F 2, \geq F 3$ and $F 4$, respectively. In a retrospective study, Venkatesh et al. ${ }^{61}$ demonstrated that MR elastography performed significantly better than conventional MR imaging for staging significant fibrosis $(\geq F 2)$ (AUROC: 0.98 .9 vs. $0.71-0.82, p<0.001$ ) and cirrhosis (F4) (AUROC: 0.93 .5 vs. $0.61-0.80 .5, p<0.01$ ).

The pooled diagnostic performances of MR elastography for LF staging, as reported by several meta-analyses, were good to excellent. Singh et al. ${ }^{62}$ conducted a meta-analysis of 12 retrospective studies and reported that, with liver biopsy as the gold standard, MR elastography demonstrated mean AUROCs of $0.84,0.88,0.93$ and 0.92 for LF stage $\geq F 1, \geq F 2$, $\geq F 3$ and F4, respectively. Their results suggested that MR elastography yielded excellent diagnostic accuracy for staging advanced fibrosis ( $\geq F 3$ ) to cirrhosis (F4) and good performance regarding significant $(\geq F 2)$ and mild fibrosis ( $\geq \mathrm{F} 1$ ) independent of sex, obesity, and etiology of CLD.

Using NAFLD cohorts, two cross-sectional prospective studies established head-to-head comparisons between MR elastography and TE for LF diagnosis in sequential patients. Park et al. ${ }^{63}$ consecutively enrolled 104 patients who underwent MR elastography, TE and liver biopsy in the United States. They demonstrated superior performance of MR elastography over TE in detecting any fibrosis ( $\geq F 1$ vs. F0) (AUROC: 0.82 vs. $0.67, p=0.0116$ ), with cut-off values of $2.65 \mathrm{kPa}$ for MR elastography and $6.10 \mathrm{kPa}$ for TE, respectively. However, MR elastography did not increase accuracy for diagnosing other LF stages. This finding was not consistent with those of the other study, conducted by Imajo et al. ${ }^{64}$ in a Japanese cohort. Imajo et al. ${ }^{64}$ revealed that MR elastography was significantly more accurate than TE in diagnosing significant fibrosis ( $\geq F 2$ vs. F0-1), advanced fibrosis ( $\geq F 3$ vs. FO-2) and cirrhosis (F4 vs. F0-3), but not in any fibrosis $(\geq F 1$ vs. F0). This variation may have been attributed to the geographic heterogeneity of the included subjects and different cut-off values applied for each LF stage. Hence, further large scale prospective studies are encouraged to determine the optimal cut-off values of each LF stage for Western and Asian NAFLD populations.

Another prospective cross-sectional study was performed to compare the diagnostic accuracies between MR elastography and pSWE for LF in NAFLD patients. Cui et al. ${ }^{65}$ reported significantly higher accuracy of MR elastography than pSWE in detecting any fibrosis ( $\geq F 1$ vs. F0) (AUROC: 0.799 vs. 0.644 , $p=0.012)$, especially in patients with class II obesity ( $p=$ 0.007 ), but the differences were not significant for other LF stages.

MR elastography is highly accurate for diagnosing advanced fibrosis ( $\geq F 3$ ) and cirrhosis (F4). This technique is robust, and therefore is feasible in obese patients and those with ascites. MR elastography is more sensitive for staging LF compared with other MR techniques. When compared with the US-based elastography techniques, MR elastography allows evaluation of a larger proportion of the liver, which is likely to reduce the sampling variability for patient monitoring over time.

However, MR elastography is limited on account of its high cost, long examination time, restricted product availability and its reliance on patient cooperation for breath-holds. Moreover, liver stiffness measurement with MR elastography may be affected in cases with hepatic iron overload, steatosis, vascular congestion or cholestasis. Therefore, further efforts are required to address the above limitations of MR elastography in liver imaging.

Diffusion-weighted MR imaging (DWI): DWI is a MR technique quantitatively assessing the random thermal diffusion ability of protons within the tissue, which is characterized by the parameter apparent diffusion coefficient (ADC). ${ }^{66}$ Fibrotic liver tissue usually manifests restricted diffusion; hence, the ADC value of the fibrotic tissue is significantly lower than that of the normal liver parenchyma. Therefore, $A D C$ values are found to be negatively correlated with LF stages in most cases ${ }^{67,68}$ (Fig. 5).

A recent meta-analysis ${ }^{68}$ demonstrated DWI to have good diagnostic accuracy for staging LF, and the AUROC was 0.8554 for $L F \geq F 1,0.8770$ for $\geq F 2,0.8836$ for $\geq F 3$ and 0.8596 for F4, respectively. Additional diagnostic benefits could be achieved when incorporating the novel DWIderived intravoxel incoherent motion model into the conventional DWI for patients with LF. ${ }^{68,69}$

DWI is robust, reproducible, widely available and relatively easy to perform compared with other emerging MR techniques in LF evaluation. However, several challenges stand in the way of using diffusion parameters as surrogate markers for LF assessment. First, perfusion, iron overload, hepatic steatosis, liver inflammation and edema can confound the interpretation of diffusion parameters. ${ }^{54}$ Second, DWI is sensitive to motion-related artifacts and susceptibility, thus it may be challenging to obtain images with enough quality to conduct reliable quantitative analyses. ${ }^{54}$ Most importantly, the acquisition standardization of the ADC is of great value but challenging to achieve because DWI relies significantly on several imaging parameters such as field strength and $b$ values. Therefore, intensive large-scale prospective studies are encouraged to focus on standardization of DWI and search for the best cut-offs of ADC value for each LF stage. ${ }^{68}$

Gadoxetic acid disodium (Gd-EOB-DTPA): Gd-EOBDTPA is an emerging hepatocyte-specific hepatobiliary MR contrast material capable of, in a single examination, 

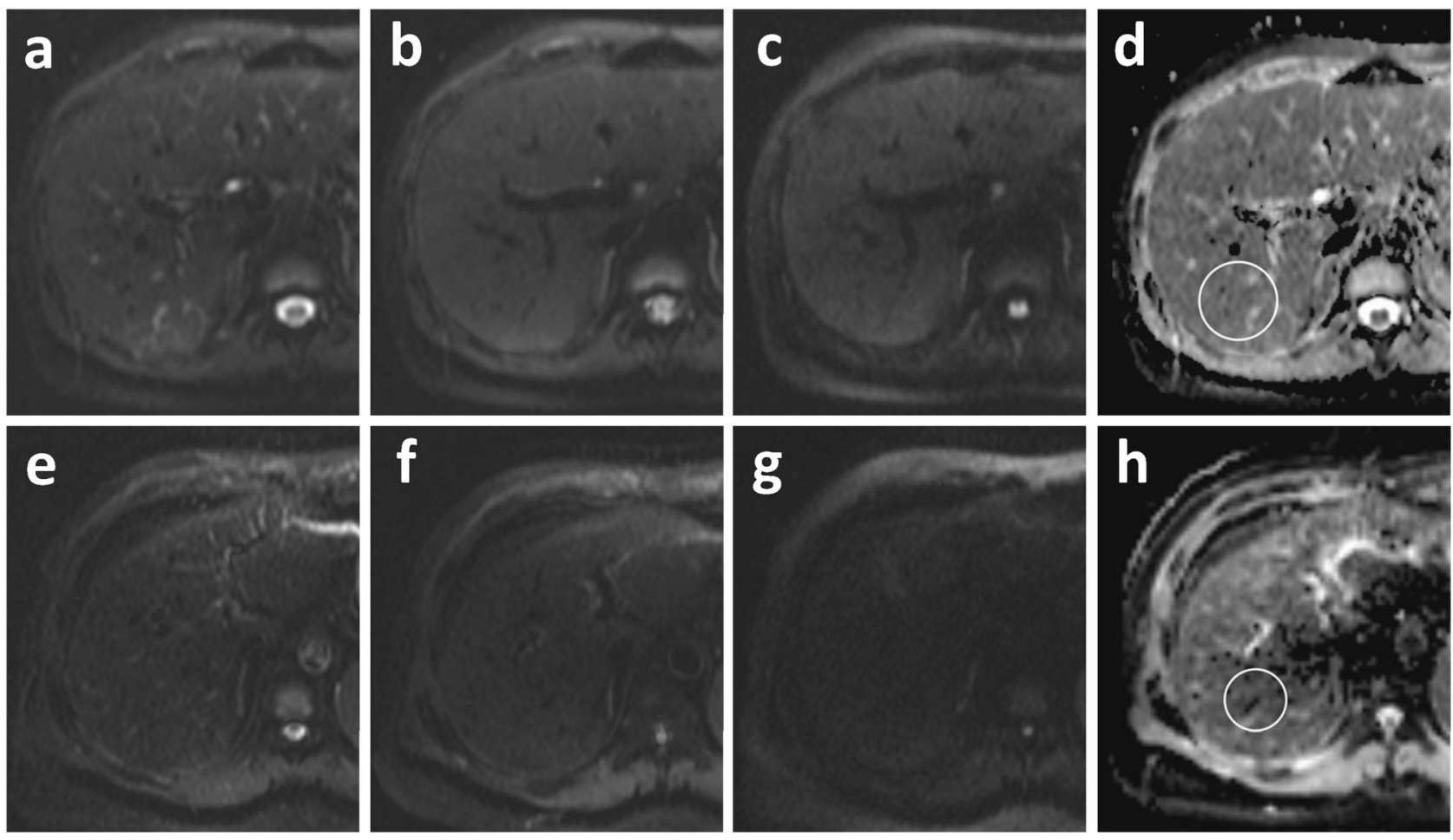

Fig. 5. Diffusion-weighted MR imaging in a 29-year-old female with normal liver (a-d) and a 44-year old male with liver cirrhosis (e-h). Images obtained with increasing b values of $0(\mathrm{a}, \mathrm{e}), 50(\mathrm{~b}, \mathrm{f})$, and $1000(\mathrm{c}, \mathrm{g}) \mathrm{sec} / \mathrm{mm}^{2}$ at 3T show a progressive reduction in signal intensity of the liver; however, the reduction is more significant in cirrhotic liver. $(d, h)$ Corresponding ADC maps generated under the monoexponential model show that the mean ADC values of the circular regions of interest of the normal and cirrhotic liver are about $0.9310^{-3} \mathrm{~mm}^{2} / \mathrm{sec}$ and $0.5410^{-3} \mathrm{~mm}^{2} / \mathrm{sec}$, respectively.

providing both the hemodynamic information during dynamic phases and good lesion characterization concerning hepatocyte function in the hepatobiliary phase (HBP) of the lesion. ${ }^{70}$

Gd-EOB-DTPA-enhanced MR imaging can optimize detection and differentiation of focal liver lesions, especially HCCs, in cirrhotic patients. During hepatocarcinogenesis, the uptake of Gd-EOB-DTPA by hepatocytes decreases progressively as a result of hepatic dysfunction. Therefore, most HCCs appear as hypointense foci in HBP. ${ }^{70}$ This enhancement pattern helps to differentiate HCCs, especially early HCCs with diagnostic confusions, from the hyper- or isointense dysplastic and regenerative nodules in $\mathrm{HBP}^{71-74}$ However, HBP hypointensity is not specific for HCC because it can be found in some iron-rich dysplastic nodules ${ }^{75}$ and nonhepatocyte containing lesions, such as hemangioma, cholangiocarcinoma and metastases. ${ }^{76}$

MR imaging with Gd-EOB-DTPA can be applied to measure preoperative liver function in patients with cirrhosis. Quantitative analysis of Gd-EOB-DTPA uptake can help evaluate liver function, determine the optimal timing for liver resection, transplantation or invasive procedures, such as transjugular intrahepatic portosystemic shunt insertion, and predict postoperative liver failure risk. ${ }^{77-79}$

MR perfusion imaging: During the process of fibrosis, as liver parenchymal blood flow velocity and portal venous flow decrease progressively, hepatic arterial flow and formation of intrahepatic shunts usually increase over time. ${ }^{54}$ These hemodynamic alterations can be tracked with MR perfusion imaging. Several previous studies in patients with CLDs have demonstrated its feasibility in LF staging. ${ }^{80,81}$
Nevertheless, liver perfusion can be affected by systemic factors, such as the cardiac status and fasting state, or regional factors, including hepatic congestion, inflammation and space-occupying lesions. Therefore, liver perfusion may not correlate exclusively with LF stage. Moreover, image analysis of MR perfusion imaging is a time-consuming procedure and the image quality of small hepatic nodules is often poor, leading to the need of a second contrast agent injection.

\section{Conclusions}

Early diagnosis and accurate staging of LF can facilitate timely patient care and optimize prognoses. In order to address the limitations of liver biopsy, imaging approaches comprising US-, CT- and MR imaging-based techniques are applied to assess LF noninvasively. Conventional US, CT and MR imaging can detect morphologic liver changes and signs of LF-related complications in patients with end-stage fibrosis, but they have limited diagnostic capacity in less advanced fibrosis. Novel imaging techniques have significantly improved LF diagnosis and staging since their introductions. Among them, TE is most widely available and extensively validated with good reproducibility and reasonable cost, and hence is the modality preferred for LF staging in the setting of routine clinical practice. MR elastography is another modality which is gaining increasing popularity, especially in academic medical centers. Nevertheless, future studies are warranted to further explore these novel imaging techniques over the entire etiology and severity spectrum of LF, before they can be widely implemented in routine clinical practice. 


\section{Acknowledgments}

This study was funded by the National Natural Science Foundation of China (Grant Number 81471658).

\section{Conflict of interest}

The authors have no conflict of interests related to this publication.

\section{Author contributions}

Contributed to manuscript writing ( $\mathrm{HJ}, \mathrm{TZ})$, material support $(T D, J C)$ and critical revision and funding of the article (BS).

\section{References}

[1] Friedman SL. Mechanisms of disease: Mechanisms of hepatic fibrosis and therapeutic implications. Nat Clin Pract Gastroenterol Hepatol 2004;1:98105. doi: 10.1038/ncpgasthep0055.

[2] Schuppan D, Afdhal NH. Liver cirrhosis. Lancet 2008;371:838-851. doi: 10. 1016/S0140-6736(08)60383-9.

[3] Schweitzer A, Horn J, Mikolajczyk RT, Krause G, Ott J]. Estimations of worldwide prevalence of chronic hepatitis $B$ virus infection: a systematic review of data published between 1965 and 2013. Lancet 2015;386:1546-1555. doi: 10.1016/S0140-6736(15)61412-X.

[4] Marcellin P, Gane E, Buti M, Afdhal N, Sievert W, Jacobson IM, et al. Regression of cirrhosis during treatment with tenofovir disoproxil fumarate for chronic hepatitis B: a 5-year open-label follow-up study. Lancet 2013;381: 468-475. doi: 10.1016/S0140-6736(12)61425-1.

[5] Bravo AA, Sheth SG, Chopra S. Liver biopsy. N Engl J Med 2001;344:495500. doi: 10.1056/NEJM200102153440706

[6] Intraobserver and interobserver variations in liver biopsy interpretation in patients with chronic hepatitis C. The French METAVIR Cooperative Study Group. Hepatology 1994;20:15-20. doi: 10.1002/hep.1840200104.

[7] Bedossa $P$, Dargère $D$, Paradis V. Sampling variability of liver fibrosis in chronic hepatitis C. Hepatology 2003;38:1449-1457. doi: 10.1016/j.hep. 2003.09.022

[8] Procopet B, Berzigotti A. Diagnosis of cirrhosis and portal hypertension: imaging, non-invasive markers of fibrosis and liver biopsy. Gastroenterol Rep (Oxf) 2017;5:79-89. doi: 10.1093/gastro/gox012.

[9] Kim MY, Jeong WK, Baik SK. Invasive and non-invasive diagnosis of cirrhosis and portal hypertension. World J Gastroenterol 2014;20:4300-4315. doi: 10.3748/wjg.v20.i15.4300.

[10] Ito K, Mitchell DG. Imaging diagnosis of cirrhosis and chronic hepatitis. Intervirology 2004;47:134-143. doi: 10.1159/000078465.

[11] Colli A, Fraquelli M, Andreoletti M, Marino B, Zuccoli E, Conte D. Severe liver fibrosis or cirrhosis: accuracy of US for detection-analysis of 300 cases. Radiology 2003;227:89-94. doi: 10.1148/radiol.2272020193.

[12] Aubé C, Oberti F, Korali N, Namour MA, Loisel D, Tanguy JY, et al. Ultrasonographic diagnosis of hepatic fibrosis or cirrhosis. J Hepatol 1999;30:472478. doi: 10.1016/S0168-8278(99)80107-X.

[13] Chen CH, Lin ST, Yang CC, Yeh YH, Kuo CL, Nien CK. The accuracy of sonography in predicting steatosis and fibrosis in chronic hepatitis C. Dig Dis Sci 2008;53:1699-1706. doi: 10.1007/s10620-007-0048-2.

[14] Bernatik T, Strobel D, Hahn EG, Becker D. Doppler measurements: a surrogate marker of liver fibrosis? Eur J Gastroenterol Hepatol 2002;14:383-387. doi: 10.1097/00042737-200204000-00008.

[15] Colli A, Cocciolo M, Mumoli N, Cattalini N, Fraquelli M, Conte D. Hepatic artery resistance in alcoholic liver disease. Hepatology 1998;28:1182-1186. doi: 10.1002/hep.510280503.

[16] Grier S, Lim AK, Patel N, Cobbold JF, Thomas HC, Cox IJ, et al. Role of microbubble ultrasound contrast agents in the non-invasive assessment of chronic hepatitis C-related liver disease. World J Gastroenterol 2006;12:34613465. doi: 10.3748/wjg.v12.i22.3461.

[17] Blomley MJ, Lim AK, Harvey CJ, Patel N, Eckersley RJ, Basilico R, et al. Liver microbubble transit time compared with histology and Child-Pugh score in diffuse liver disease: a cross sectional study. Gut 2003;52:1188-1193. doi: 10.1136/gut.52.8.1188.

[18] Lim AK, Taylor-Robinson SD, Patel N, Eckersley RJ, Goldin RD, Hamilton G, et al. Hepatic vein transit times using a microbubble agent can predict disease severity non-invasively in patients with hepatitis C. Gut 2005;54:128-133. doi: 10.1136/gut.2003.030965.

[19] Kim MY, Suk KT, Baik SK, Kim HA, Kim YJ, Cha SH, et al. Hepatic vein arrival time as assessed by contrast-enhanced ultrasonography is useful for the assessment of portal hypertension in compensated cirrhosis. Hepatology 2012;56:1053-1062. doi: 10.1002/hep.25752

[20] Talwalkar JA. Elastography for detecting hepatic fibrosis: options and considerations. Gastroenterology 2008;135:299-302. doi: 10.1053/j.gastro. 2008.05.038.

[21] Muthupillai R, Lomas DJ, Rossman PJ, Greenleaf JF, Manduca A, Ehman RL. Magnetic resonance elastography by direct visualization of propagating acoustic strain waves. Science 1995;269:1854-1857. doi: 10.1126/science. 7569924.

[22] Yoneda M, Suzuki K, Kato S, Fujita K, Nozaki Y, Hosono K, et al. Nonalcoholic fatty liver disease: US-based acoustic radiation force impulse elastography. Radiology 2010;256:640-647. doi: 10.1148/radiol.10091662.

[23] Tang A, Cloutier G, Szeverenyi NM, Sirlin CB. Ultrasound elastography and MR elastography for assessing liver fibrosis: Part 1, principles and techniques. AJR Am J Roentgenol 2015;205:22-32. doi: 10.2214/AJR.15.14552.

[24] Sigrist RMS, Liau J, Kaffas AE, Chammas MC, Willmann JK. Ultrasound elastography: review of techniques and clinical applications. Theranostics 2017; 7:1303-1329. doi: 10.7150/thno.18650.

[25] Castéra L, Vergniol J, Foucher J, Le Bail B, Chanteloup E, Haaser M, et al. Prospective comparison of transient elastography, Fibrotest, APRI, and liver biopsy for the assessment of fibrosis in chronic hepatitis C. Gastroenterology 2005;128:343-350. doi: 10.1053/j.gastro.2004.11.018.

[26] Ziol M, Handra-Luca A, Kettaneh A, Christidis C, Mal F, Kazemi F, et al. Noninvasive assessment of liver fibrosis by measurement of stiffness in patients with chronic hepatitis C. Hepatology 2005;41:48-54. doi: 10.1002/hep.20506.

[27] Castera L, Forns X, Alberti A. Non-invasive evaluation of liver fibrosis using transient elastography. J Hepatol 2008;48:835-847. doi: 10.1016/j.jhep. 2008.02.008.

[28] Sporea I, Sirli R, Deleanu A, Tudora A, Curescu M, Cornianu M, et al. Comparison of the liver stiffness measurement by transient elastography with the liver biopsy. World J Gastroenterol 2008;14:6513-6517. doi: 10. 3748/wjg.14.6513.

[29] Friedrich-Rust M, Ong MF, Martens S, Sarrazin C, Bojunga J, Zeuzem S, et al. Performance of transient elastography for the staging of liver fibrosis: a metaanalysis. Gastroenterology 2008;134:960-974. doi: 10.1053/j.gastro.2008. 01.034.

[30] Tsochatzis EA, Gurusamy KS, Ntaoula S, Cholongitas E, Davidson BR, Burroughs AK. Elastography for the diagnosis of severity of fibrosis in chronic liver disease: a meta-analysis of diagnostic accuracy. J Hepatol 2011;54:650-659. doi: 10.1016/j.jhep.2010.07.033.

[31] EASL Clinical Practice Guidelines: management of hepatitis C. virus infection. J Hepatol 2011;55:245-264. doi: 10.1016/j.jhep.2011.02.023.

[32] Singh S, Muir AJ, Dieterich DT, Falck-Ytter YT. American Gastroenterological Association institute technical review on the role of elastography in chronic liver diseases. Gastroenterology 2017;152:1544-1577. doi: 10.1053/j. gastro.2017.03.016

[33] Cosgrove D, Piscaglia F, Bamber J, Bojunga J, Correas JM, Gilja OH, et al. EFSUMB guidelines and recommendations on the clinical use of ultrasound elastography. Part 2: Clinical applications. Ultraschall Medx 2013;34:238253. doi: $10.1055 / \mathrm{s}-0033-1335375$.

[34] Castéra L, Sebastiani G, Le Bail B, de Lédinghen V, Couzigou P, Alberti A. Prospective comparison of two algorithms combining non-invasive methods for staging liver fibrosis in chronic hepatitis C. J Hepatol 2010;52:191-198. doi: 10.1016/j.jhep.2009.11.008.

[35] Boursier J, de Ledinghen V, Zarski JP, Fouchard-Hubert I, Gallois Y, Oberti F, et al. Comparison of eight diagnostic algorithms for liver fibrosis in hepatitis C: new algorithms are more precise and entirely noninvasive. Hepatology 2012;55:58-67. doi: 10.1002/hep.24654.

[36] Sebastiani G, Vario A, Guido M, Alberti A. Sequential algorithms combining non-invasive markers and biopsy for the assessment of liver fibrosis in chronic hepatitis B. World J Gastroenterol 2007;13:525-531. doi: 10. 3748/wjg.v13.i4.525.

[37] EASL-ALEH Clinical Practice Guidelines: Non-invasive tests for evaluation of liver disease severity and prognosis. J. Hepatol 2015;63:237-264. doi: 10 . 1016/j.jhep.2015.04.006

[38] Nightingale K, Soo MS, Nightingale R, Trahey G. Acoustic radiation force impulse imaging: in vivo demonstration of clinical feasibility. Ultrasound Med Biol 2002;28:227-235. doi: 10.1016/S0301-5629(01)00499-9.

[39] Nightingale K. Acoustic radiation force impulse (ARFI) imaging: a review. Curr Med Imaging Rev 2011;7:328-339. doi: 10.2174/157340511798038657.

[40] Srinivasa Babu A, Wells ML, Teytelboym OM, Mackey JE, Miller FH, Yeh BM, et al. Elastography in chronic liver disease: modalities, techniques, limitations, and future directions. Radiographics 2016;36:1987-2006. doi: 10.1148/rg. 2016160042.

[41] Bota S, Herkner H, Sporea I, SalzI P, Sirli R, Neghina AM, et al. Meta-analysis: ARFI elastography versus transient elastography for the evaluation of liver fibrosis. Liver Int 2013;33:1138-1147. doi: 10.1111/liv.12240.

[42] Bercoff J, Tanter M, Fink M. Supersonic shear imaging: a new technique for soft tissue elasticity mapping. IEEE Trans Ultrason Ferroelectr Freq Control 2004;51:396-409. doi: 10.1109/TUFFC.2004.1295425. 
[43] Muller M, Gennisson JL, Deffieux T, Tanter M, Fink M. Quantitative viscoelasticity mapping of human liver using supersonic shear imaging: preliminary in vivo feasibility study. Ultrasound Med Biol 2009;35:219-229. doi: 10. 1016/j.ultrasmedbio.2008.08.018.

[44] Sirli R, Bota S, Sporea I, Jurchis A, Popescu A, Gradinaru-Tascău O, et al. Liver stiffness measurements by means of supersonic shear imaging in patients without known liver pathology. Ultrasound Med Biol 2013;39: 1362-1367. doi: 10.1016/j.ultrasmedbio.2013.03.021.

[45] Sporea I, Bota S, Jurchis A, Sirli R, Grădinaru-Tascău O, Popescu A, et al. Acoustic radiation force impulse and supersonic shear imaging versus transient elastography for liver fibrosis assessment. Ultrasound Med Biol 2013; 39:1933-1941. doi: 10.1016/j.ultrasmedbio.2013.05.003.

[46] Leung VY, Shen J, Wong VW, Abrigo J, Wong GL, Chim AM, et al. Quantitative elastography of liver fibrosis and spleen stiffness in chronic hepatitis $B$ carriers: comparison of shear-wave elastography and transient elastography with liver biopsy correlation. Radiology 2013;269:910-918. doi: 10.1148/radiol. 13130128.

[47] Bavu E, Gennisson JL, Couade M, Bercoff J, Mallet V, Fink M, et al. Noninvasive in vivo liver fibrosis evaluation using supersonic shear imaging: a clinical study on 113 hepatitis C virus patients. Ultrasound Med Biol 2011;37:13611373. doi: 10.1016/j.ultrasmedbio.2011.05.016.

[48] Ferraioli G, Tinelli C, Dal Bello B, Zicchetti M, Filice G, Filice C. Accuracy of realtime shear wave elastography for assessing liver fibrosis in chronic hepatitis C: a pilot study. Hepatology 2012;56:2125-2133. doi: 10.1002/hep.25936.

[49] Bruix J, Sherman M. Management of hepatocellular carcinoma: an update. Hepatology 2011;53:1020-1022. doi: 10.1002/hep.24199.

[50] EASL-EORTC Clinical practice guidelines: management of hepatocellular carcinoma. J. Hepatol 2012;56:908-943. doi: 10.1016/j.jhep.2011.12.001.

[51] Talakić E, Schaffellner S, Kniepeiss D, Mueller H, Stauber R, Quehenberger F, et al. CT perfusion imaging of the liver and the spleen in patients with cirrhosis: Is there a correlation between perfusion and portal venous hypertension? Eur Radiol 2017;27:4173-4180. doi: 10.1007/s00330-017-4788-x.

[52] Guan S, Zhao WD, Zhou KR, Peng WJ, Mao J, Tang F. CT perfusion at early stage of hepatic diffuse disease. World J Gastroenterol 2005;11:3465-3467. doi: 10.3748/wjg.v11.i22.3465.

[53] Van Beers BE, Leconte I, Materne R, Smith AM, Jamart J, Horsmans Y. Hepatic perfusion parameters in chronic liver disease: dynamic CT measurements correlated with disease severity. AJR Am J Roentgenol 2001;176: 667-673. doi: 10.2214/ajr.176.3.1760667.

[54] Faria SC, Ganesan K, Mwangi I, Shiehmorteza M, Viamonte B, Mazhar S, et al. MR imaging of liver fibrosis: current state of the art. Radiographics 2009; 29:1615-1635. doi: 10.1148/rg.296095512.

[55] Manduca A, Oliphant TE, Dresner MA, Mahowald JL, Kruse SA, Amromin E, et al. Magnetic resonance elastography: non-invasive mapping of tissue elasticity. Med Image Anal 2001;5:237-254. doi: 10.1016/S1361-8415(00)00039-6.

[56] Talwalkar JA, Yin M, Fidler JL, Sanderson SO, Kamath PS, Ehman RL. Magnetic resonance imaging of hepatic fibrosis: emerging clinical applications. Hepatology 2008;47:332-342. doi: 10.1002/hep.21972.

[57] Huwart L, Sempoux C, Salameh N, Jamart J, Annet L, Sinkus R, et al. Liver fibrosis: noninvasive assessment with MR elastography versus aspartate aminotransferase-to-platelet ratio index. Radiology 2007;245:458-466. doi: 10.1148/radiol.2452061673.

[58] Huwart L, Sempoux C, Vicaut E, Salameh N, Annet L, Danse E, et al. Magnetic resonance elastography for the noninvasive staging of liver fibrosis. Gastroenterology 2008;135:32-40. doi: 10.1053/j.gastro.2008.03.076.

[59] Asbach P, Klatt D, Schlosser B, Biermer M, Muche M, Rieger A, et al. Viscoelasticity-based staging of hepatic fibrosis with multifrequency MR elastography. Radiology 2010;257:80-86. doi: 10.1148/radiol.10092489.

[60] Wang Y, Ganger DR, Levitsky J, Sternick LA, McCarthy RJ, Chen ZE, et al. Assessment of chronic hepatitis and fibrosis: comparison of MR elastography and diffusion-weighted imaging. AJR Am J Roentgenol 2011;196:553-561. doi: 10.2214/AJR.10.4580.

[61] Venkatesh SK, Yin M, Takahashi N, Glockner JF, Talwalkar JA, Ehman RL. Noninvasive detection of liver fibrosis: MR imaging features vs. MR elastography. Abdom Imaging 2015;40:766-775. doi: 10.1007/s00261-015-0347-6.

[62] Singh S, Venkatesh SK, Loomba R, Wang Z, Sirlin C, Chen J, et al. Magnetic resonance elastography for staging liver fibrosis in non-alcoholic fatty liver disease: a diagnostic accuracy systematic review and individual participant data pooled analysis. Eur Radiol 2016;26:1431-1440. doi: 10.1007/s00330015-3949-z.
[63] Park CC, Nguyen P, Hernandez C, Bettencourt R, Ramirez K, Fortney L, et al. Magnetic resonance elastography vs transient elastography in detection of fibrosis and noninvasive measurement of steatosis in patients with biopsyproven nonalcoholic fatty liver disease. Gastroenterology 2017;152:598607.e2. doi: $10.1053 /$ j.gastro.2016.10.026.

[64] Imajo K, Kessoku T, Honda Y, Tomeno W, Ogawa Y, Mawatari H, et al. Magnetic resonance imaging more accurately classifies steatosis and fibrosis in patients with nonalcoholic fatty liver disease than transient elastography. Gastroenterology 2016;150:626-637.e7. doi: 10.1053/j.gastro.2015.11.048.

[65] Cui J, Heba E, Hernandez C, Haufe W, Hooker J, Andre MP, et al. Magnetic resonance elastography is superior to acoustic radiation force impulse for the Diagnosis of fibrosis in patients with biopsy-proven nonalcoholic fatty liver disease: A prospective study. Hepatology 2016;63:453-461. doi: 10. 1002/hep.28337.

[66] Taouli B, Koh DM. Diffusion-weighted MR imaging of the liver. Radiology 2010;254:47-66. doi: 10.1148/radiol.09090021.

[67] Wang QB, Zhu H, Liu HL, Zhang B. Performance of magnetic resonance elastography and diffusion-weighted imaging for the staging of hepatic fibrosis: A meta-analysis. Hepatology 2012;56:239-247. doi: 10.1002/hep.25610.

[68] Jiang H, Chen J, Gao R, Huang Z, Wu M, Song B. Liver fibrosis staging with diffusion-weighted imaging: a systematic review and meta-analysis. Abdom Radiol (NY) 2017;42:490-501. doi: 10.1007/s00261-016-0913-6.

[69] Luciani A, Vignaud A, Cavet M, Nhieu JT, Mallat A, Ruel L, et al. Liver cirrhosis: intravoxel incoherent motion MR imaging-pilot study. Radiology 2008;249: 891-899. doi: 10.1148/radiol.2493080080.

[70] Van Beers BE, Pastor CM, Hussain HK. Primovist, Eovist: what to expect? J Hepatol 2012;57:421-429. doi: 10.1016/j.jhep.2012.01.031.

[71] Kierans AS, Kang SK, Rosenkrantz AB. The diagnostic performance of dynamic contrast-enhanced MR imaging for detection of small hepatocellular carcinoma measuring up to $2 \mathrm{~cm}$ : a meta-analysis. Radiology $2016 ; 278: 82-$ 94. doi: 10.1148/radiol.2015150177.

[72] Kitao A, Matsui O, Yoneda N, Kozaka K, Kobayashi S, Koda W, et al. Hypervascular hepatocellular carcinoma: correlation between biologic features and signal intensity on gadoxetic acid-enhanced MR images. Radiology 2012; 265:780-789. doi: 10.1148/radiol.12120226.

[73] Narita M, Hatano E, Arizono S, Miyagawa-Hayashino A, Isoda H, Kitamura K, et al. Expression of OATP1B3 determines uptake of Gd-EOB-DTPA in hepatocellular carcinoma. J Gastroenterol 2009;44:793-798. doi: 10.1007/ s00535-009-0056-4.

[74] Lee MH, Kim SH, Park MJ, Park CK, Rhim H. Gadoxetic acid-enhanced hepatobiliary phase MRI and high-b-value diffusion-weighted imaging to distinguish well-differentiated hepatocellular carcinomas from benign nodules in patients with chronic liver disease. AJR Am J Roentgenol 2011;197:W868W875. doi: 10.2214/AJR.10.6237.

[75] Choi JY, Lee JM, Sirlin CB. CT and MR imaging diagnosis and staging of hepatocellular carcinoma: part I. Development, growth, and spread: key pathologic and imaging aspects. Radiology 2014;272:635-654. doi: 10 . 1148 /radiol.14132361.

[76] Seale MK, Catalano OA, Saini S, Hahn PF, Sahani DV. Hepatobiliary-specific MR contrast agents: role in imaging the liver and biliary tree. Radiographics 2009;29:1725-1748. doi: 10.1148/rg.296095515.

[77] Yamada A, Hara T, Li F, Fujinaga Y, Ueda K, Kadoya M, et al. Quantitative evaluation of liver function with use of gadoxetate disodium-enhanced MR imaging. Radiology 2011;260:727-733. doi: 10.1148/radiol.11100586.

[78] Cho SH, Kang UR, Kim JD, Han YS, Choi DL. The value of gadoxetate disodium-enhanced MR imaging for predicting posthepatectomy liver failure after major hepatic resection: a preliminary study. Eur J Radiol 2011;80: e195-e200. doi: 10.1016/j.ejrad.2011.08.008.

[79] Zipprich A, Kuss O, Rogowski S, Kleber G, Lotterer E, Seufferlein T, et al. Incorporating indocyanin green clearance into the Model for End Stage Liver Disease (MELD-ICG) improves prognostic accuracy in intermediate to advanced cirrhosis. Gut 2010;59:963-968. doi: 10.1136/gut.2010.208595.

[80] Hagiwara M, Rusinek H, Lee VS, Losada M, Bannan MA, Krinsky GA, et al. Advanced liver fibrosis: diagnosis with 3D whole-liver perfusion MR imaginginitial experience. Radiology 2008;246:926-934. doi: 10.1148/radiol. 2463070077.

[81] Chen BB, Hsu CY, Yu CW, Wei SY, Kao JH, Lee HS, et al. Dynamic contrastenhanced magnetic resonance imaging with Gd-EOB-DTPA for the evaluation of liver fibrosis in chronic hepatitis patients. Eur Radiol 2012;22:171-180. doi: $10.1007 / \mathrm{s} 00330-011-2249-5$. 